Jurnal Geocelebes Vol. 5 No. 1, April 2021, 80 - 90

\title{
PEMETAAN DAERAH RAWAN LONGSOR MENGGUNAKAN METODE PENCITRAAN SATELIT DI KABUPATEN ENREKANG SULAWESI SELATAN
}

\author{
Paisa*, Muh Said L, Ayusari Wahyuni \\ Jurusan Fisika, Fakultas Sains dan Teknologi, UIN Alauddin Makassar, Indonesia \\ *Corresponding author. Email: paisalakami02@gmail.com
}

Manuscript received: 12 January 2021; Received in revised form: 17 April 2021; Accepted: 30 April 2021

\begin{abstract}
Abstrak
Telah dilakukan penelitian yang bertujuan untuk pembuatan peta zona rawan longsor di Kabupaten Enrekang. Daerah yang dianggap rawan terhadap longsor dapat dianalisis dan diinterpretasi dengan menggunakan data raster berupa citra pengindraan jauh satelit dan SIG (Sistem Informasi Geografis). Penelitian ini menggunakan beberapa data seperti curah hujan, geologi, jenis tanah, penggunan lahan, geomorfologi vegetasi serta kemiringan lereng. Hasil yang diperoleh dari analisis data tersebut berupa peta rawan longsor di Kabupaten Enrekang Sulawesi Selatan yang diklasifikasikan menjadi tiga kelas yaitu kelas tidak rawan, kelas rawan dan kelas sangat rawan. Tingkat tertinggi adalah rawan sebesar 56,19\% atau sekitar 101.364,81 Ha yang meliputi Kecamatan Butu Batu, Maiwa, Kulo, Pancariajang, Pituriawa, Bungi, Baraka, Aggaraja, Alla, Masselle, Curio, dan sebagian kecil daerah di Kecamatan Enrekang serta Candana.
\end{abstract}

Kata Kunci: citra; Landsat 8; pemetaan; SIG; tanah longsor.

\begin{abstract}
Research has been carried out aimed at making a landslide-prone zone map in Enrekang district. Areas that are considered prone to landslides can be analyzed and interpreted using raster data in the form of satellite remote sensing images and GIS (Geographic Information System). This research using data such as rainfall, geology, soil type, land use, vegetation, geomorphology and slope. From the data analysis in the form of landslide hazard maps in Enrekang district, South Sulawesi which are classified into three classes, namely the non-prone class, the vulnerable class and the very vulnerable class. The highest level is prone at $56.19 \%$ or around 101364.81 Ha which includes sub-districts Butu Batu, Maiwa, Kulo, Pancariajang, Pituriawa, Bungi, Baraka, Aggaraja, Alla, Masselle, Curio, and a few areas in Enrekang and Candana.
\end{abstract}

Keywords: GIS; image; Landsat 8; landslides; mapping.

\section{Pendahuluan}

Tanah longsor adalah salah satu bencana yang sering terjadi di Indonesia khususnya di daerah perbukitan dan pegunungan yang memiliki intesitas curah hujan yang sangat tinggi. Selain itu, kemiringan lereng yang curam dan struktur geologi suatu wilayah juga merupakan faktor penyebab terjadinya longsor. Tanah longsor terjadi akibat perpindahan material pembentuk lereng berupa batuan, bahan rombakan, tanah, atau material campuran tersebut, bergerak ke bawah atau keluar lereng dan salah satu dari tipe gerakan tanah (mass movement) 
mass wasting) berupa fenomena alam yang mengakibatkan terjadinya gerakan tanah yang mengikuti kemiringan lereng (Wahyuni et al., 2019; Selby, 1985).

Badan Pengendalian Dampak Lingkungan Daerah (Bapedalda) Sulawesi Selatan telah mengkategorikan beberapa wilayah di Sulawesi Selatan sebagai daerah rawan longsor terutama pada musim penghujan. Enrekang merupakan salah satu daerah tersebut.

Data yang diambil dari Badan Nasional Penanggulangan Bencana (BNPB) 2019, memperoleh hasil analisis bahwa jumlah penduduk yang tinggal di daerah bahaya longsor dari sedang sampai tinggi sebesar 40,9 juta jiwa. Data tersebut memberikan informasi bahwa masih banyak masyarakat Indonesia yang tinggal di daerah yang masuk dalam kategori rawan longsor. Hal ini dapat terjadi karena masyarakat masih kekurangan informasi yang jelas tentang daerah rawan terhadap longsor, yang berdampak pada banyaknya masyarakat yang membangun rumah di sekitar titik rawan longsor, jika daerah rawan longsor menjadi daerah yang padat penduduk maka hal tersebut dapat mengakibat tingginya resiko kerugian bagi masyarakat sekitar apabila sewaktu-waktu longsor terjadi secara tiba-tiba. Antisipasi yang dapat dilakukan adalah dengan melakukan pemetaan daerah rawan longsor sebagai upaya mitigasi bencana dan sumber informasi bagi masyarakat sekitar tentang daerah yang memiliki resiko longsor yang rendah hingga tinggi untuk mengetahui wilayah yang aman untuk bermukim atau wilayah yang aman membangun tempat tinggal secara permanen.

Salah satunya dengan memanfaatkan perkembangan Sistem Informasi Geografis (SIG) yang mampu menyediakan informasi data berupa data geospasial yang menampilkan obyek di permukaan bumi secara cepat, dan menyediakan sistem analisis keruangan yang akurat. Sehingga dapat dilakukan upaya mitigasi yang bertujuan mencegah risiko yang berpotensi menjadi bencana atau mengurangi efek dari bencana ketika bencana itu terjadi, salah satunya adalah tanah longsor (Laurensz et al., 2019).

Sistem Informasi Geografis (SIG) merupakan sistem yang dapat menganalisis data berupa spasial yang dapat digunakan dalam berbagai keperluan dalam menampilkan informasi permukaan bumi. Salah satu penggunaan dalam SIG berupa peta rawan longsor (Leng et al., 2017). Salah satu data yang dapat digunakan dalam pembuatan peta adalah data citra/ pengindraan jauh. Data ini menggunakan energi gelombang elektromagnetik. Energi gelombang ini selain didapatkan dari sinar matahari, juga didapatkan dari sumber energi lain, baik itu sumber yang sifatnya alamiah yang digunakan dalam penginderaan jauh sistem pasif, juga sumber energi buatan manusia yang digunakan dalam penginderaan jauh sistem aktif (Sutanto, 1987).

Data citra yang digunakan berupa data raster sensor optis Landsat 8. Ada pun kelebihan Landsat 8 menggunakan kombinasi RGB (Red, Green, Blue) sebagai penunjuk lokasi yang tepat yakni kanal atau band Near Infra Red (NIR-Kanal 5) (LAPAN, 2015). Dalam pengolahan data citra landsat 8, beberapa koreksi perlu dilakukan yakni berupa koreksi geometric. Koreksi ini menyamakan proyeksi citra pada suatu bidang datar (peta) yang sama dengan sistem proyeksi peta. Selain itu, koreksi radiometric juga sering dilakukan agar nilai piksel dengan mempertimbangkan faktor gangguan atmosfer sebagai sumber kesalahan utama dapat diperbaiki (Ati, 2016; LAPAN, 2015).

\section{Metode Penelitian}

Penelitian ini dilakukan di Kabupaten Enrekang, Provinsi Sulawesi Selatan. Secara geografis Kabupaten Enrekang 
terletak antara koordinat $3^{0} 14^{\prime} 36^{\prime \prime}$ $3^{0} 50^{\prime} 00^{\prime}$ Lintang Selatan, dan antara $119^{\circ} 40^{\prime} 53^{\prime \prime}$ - 120006'33" Bujur Timur dengan luas wilayah 1.786,01 $\mathrm{Km}^{2}$. Kabupaten Enrekang dengan ibukota Enrekang terletak $\pm 235 \mathrm{Km}$ sebelah utara Makassar. Batas wilayah kabupaten ini adalah sebelah utara berbatasan dengan Kabupaten Tana Toraja, sebelah timur dengan Kabupaten Luwu dan Sidrap, sebelah selatan dengan Kabupaten Sidrap dan; sebelah barat dengan Kabupaten Pinrang. Secara administratif Kabupaten Enrekang terbagi ke dalam 9 wilayah kecamatan dengan 111 desa/ kelurahan. Kecamatan terluas adalah Kecamatan Maiwa dengan luas $392,87 \mathrm{~km}^{2}$ atau sekitar
22,0 \% dari luas wilayah Kabupaten Enrekang, sedangkan kecamatan terkecil adalah Kecamatan Malua yaitu sebesar $40,36 \mathrm{~km}^{2}$ atau hanya sekitar 2,26\% dari luas total Kabupaten Enrekang (SLHD, 2006).

Data yang digunakan adalah data sekunder yaitu data citra Landsat 8 yang diperoleh dari Lembaga Antariksa Nasional (LAPAN) Pare-pare tahun 2020, data DEM Kabupaten Enrekang tahun 2020, data harian dan bulanan curah hujan Kabupaten Enrekang tahun 2018, data shapefile (SHP) penggunaan lahan, jenis tanah, dan geologi. Bagan alir dapat dilihat pada Gambar 1.

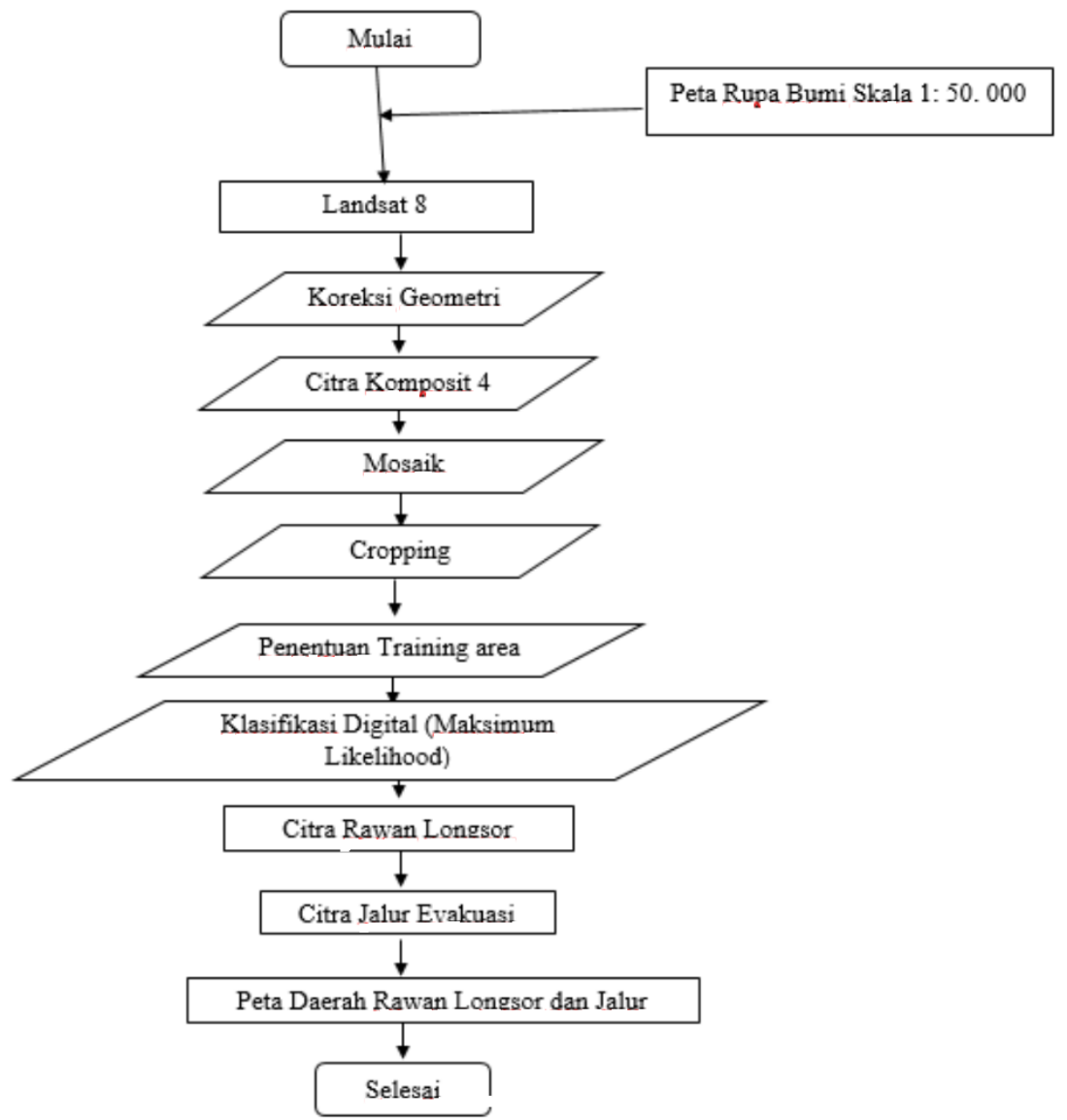

Gambar 1. Bagan alir penelitian.

\section{Hasil dan Pembahasan}

Peta rawan longsor diperoleh dari hasil dari pengolahan data parameter - parameter yang dapat menyebabkan longsor seperti curah hujan, geologi, jenis tanah, penggunaan lahan, dan vegetasi.

\section{A. Peta Curah Hujan}

Tabel 1 menampilkan persentase intensitas curah hujan dan Gambar 2 adalah Peta Sebaran Curah Hujan Harian tahun 2018 di Kabupaten Enrekang. 
Tabel 1. Persentase intensitas curah hujan di Kabupaten Enrekang.

\begin{tabular}{cccc}
\hline Kelas & Curah Hujan & Luas (Ha) & Persentase (\%) \\
\hline Sangat Rendah & $<13,6$ & $235.615 .018,3$ & 12,94 \\
Rendah & $13,6-20,7$ & $548.281 .119,4$ & 30,10 \\
Sedang & $20,7-27,7$ & $423.947 .520,5$ & 23,28 \\
Tinggi & $27,7-34,8$ & $511.471 .995,2$ & 28,08 \\
Sangat Tinggi & $>34,8$ & $102.069 .887,1$ & 5,60 \\
& & 1.821 .385 .541 & 100 \\
\hline
\end{tabular}

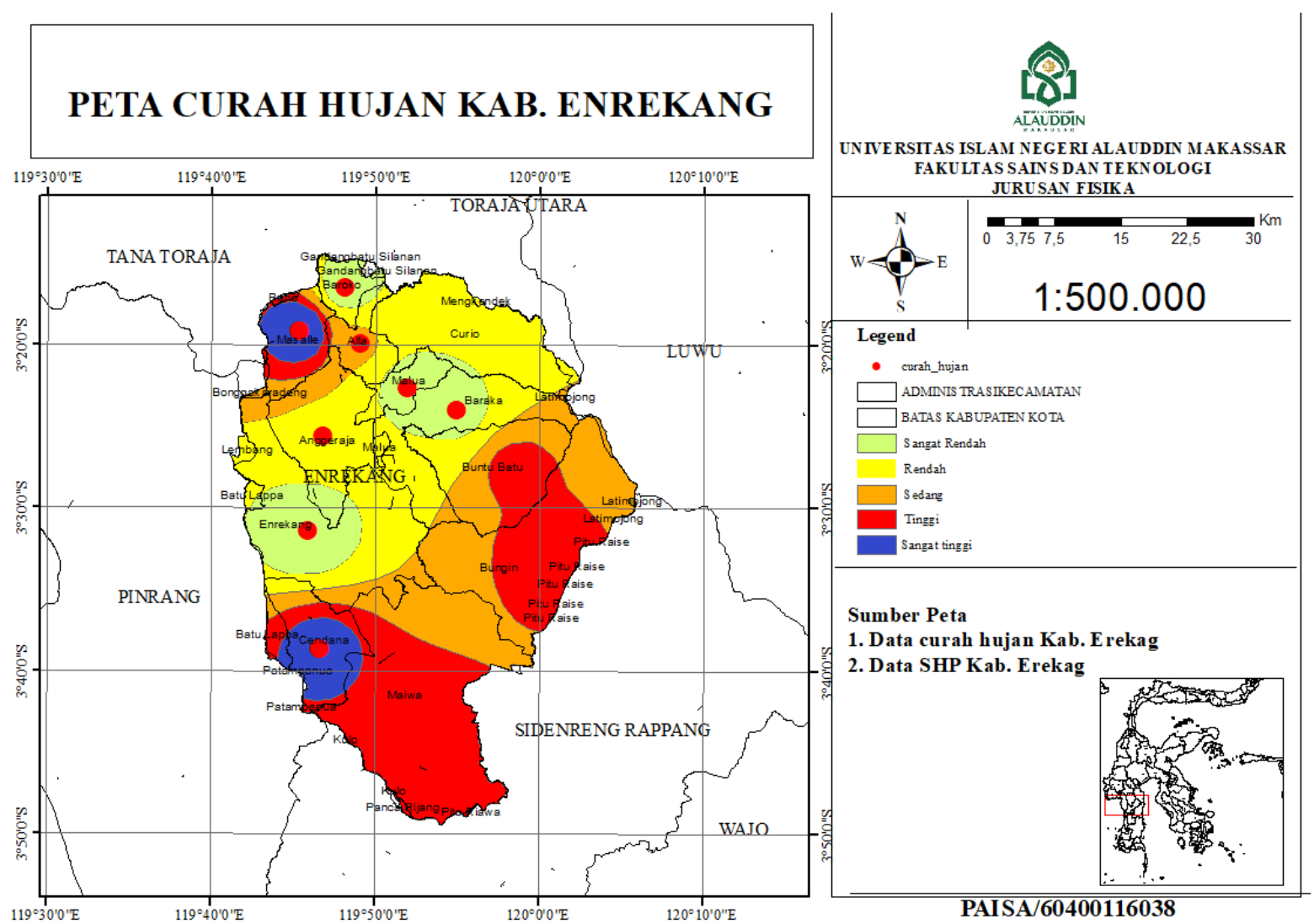

Gambar 2. Peta Curah Hujan Kabupaten Enrekang.

B. Geologi

Tabel 2. Sebaran Geologi di Kabupaten Enrekang.

\begin{tabular}{clcc}
\hline Simbol & \multicolumn{1}{c}{ Formasi } & Luas (Ha) & Persentase (\%) \\
\hline Kls & Formasi Latimojong & 40180,51 & 22,09 \\
Qa & Endapan permukaan tak bernama & 133,68 & 0,07 \\
Tets & Serpih & 48397,21 & 26,6 \\
Tmod & Napal & 4455,545 & 2,45 \\
Tmps1 & Formasi Sekala & 45,28 & 0,02 \\
Tmpss & Batupasir bersusunan andesit & 28554.71 & 15,7 \\
Tmpv & Aliran lava & 5714,23 & 3,14 \\
Tms1 & Sedimen tak bernama & 8901,81 & 4,89 \\
Tmtv & Batuan Gunungapi Talaya & 288,06 & 0,16 \\
Tom11 & Batugamping terumbu & $8.920,701$ & 4,9 \\
Tpl & Lamprofir tak bernama & $1.057,38$ & 0,58 \\
Tpw & Konglomerat & $35.284,02$ & 19,39 \\
& Jumlah & $181.933,136$ & 100 \\
\hline
\end{tabular}


Peta geologi diperoleh dengan menggabungkan antara shapefile geologi Provinsi Sulawesi Selatan dengan shapefile administrasi Kabupaten Enrekang, setelah itu melakukan pemotongan atau cropping sehingga diperolah Peta Geologi Kabupaten Enrekang.

Tabel 2 menampilkan formasi geologi pada Kabupaten Enrekang. Peta Geologi Kabupaten Enrekang dapat dilihat pada Gambar 3.

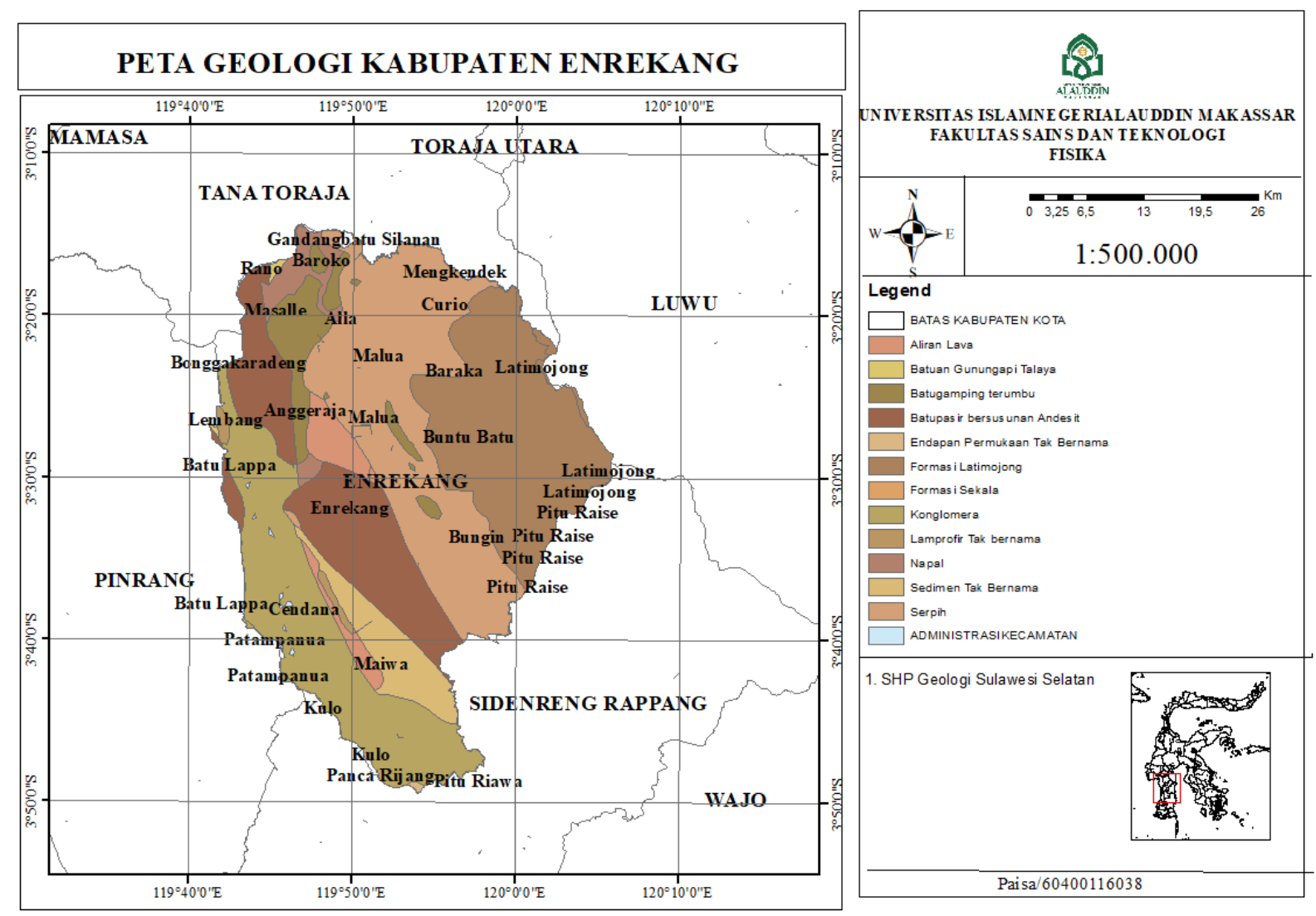

Gambar 3. Peta Geologi Kabupaten Enrekang.

\section{Jenis Tanah}

Peta jenis tanah diperoleh dengan cara overlay antara shapefile jenis tanah Provinsi Sulawesi Selatan dengan shapefile administrasi Kabupaten Enrekang. Kemudian hasil overlay tersebut dipotong agar diperoleh peta jenis tanah Kabupaten Enrekang. Tabel 3 merupakan tabel jenis tanah yang diperoleh dari tabel atribut. Sebaran jenis tanah yang ada di Kabupaten Enrekang termuat dalam peta jenis tanah pada Gambar 4 di bawah ini.

Tabel 3. Jenis Tanah di Kabupaten Enrekang.

\begin{tabular}{cccc}
\hline Tanah1 & Tanah2 & Luas (Ha) & Persentase (\%) \\
\hline Typic Endoaquepts & Typic Endoaquents & $6.749,33754$ & 3,697430917 \\
Typic Endoaquepts & Aquic Eutrudepts & 167,863419 & 0,091959157 \\
Typic Eutrudepts & Lithic Udorthents & 547,086025 & 0,299705381 \\
Typic Eutrudepts & Lithic Udorthents & $6.116,68023$ & 3,35084776 \\
ROC & Lithic Udorthents & $18.837,6253$ & 10,31965252 \\
Typic Eutrudepts & Typic Hapludults & $11.399,2617$ & 6,244758441 \\
Typic Eutrudepts & Typic Hapludults & $1.786,70515$ & 0,97879515 \\
\hline
\end{tabular}




\begin{tabular}{cccc}
\hline Aquic Eutrudepts & Typic Endoaquepts & 409,319583 & 0,224233989 \\
Typic Eutrudepts & Typic Eutrudepts & $11.187,9276$ & 6,128985141 \\
Typic Eutrudepts & Typic Hapludalfs & $3.361,80979$ & 1,841671034 \\
Lithic Dystrudepts & Lithic Hapludults & $7.402,81823$ & 4,055421562 \\
Typic Eutrudepts & Lithic Dystrudepts & $3.236,62072$ & 1,773089795 \\
Vertic Hapludalfs & Typic Eutrudepts & $7.878,80965$ & 4,316179802 \\
Typic Hapludults & Typic Eutrudepts & $9.932,13428$ & 5,441034786 \\
Typic Eutrudepts & Typic Hapludalfs & $5.654,53637$ & 3,097675509 \\
Typic Eutrudepts & Typic Hapludalfs & $6.318,47327$ & 3,461394288 \\
Typic Eutrudepts & Typic Hapludults & $3.388,60486$ & 1,856349943 \\
Typic Eutrudepts & Typic Hapludalfs & $14.561,1269$ & 7,976895588 \\
Typic Hapludults & Typic Eutrudepts & $9.885,67572$ & 5,415583801 \\
Typic Eutrudepts & Typic Hapludults & $40.176,5053$ & 22,00954569 \\
Lithic Dystrudepts & Lithic Haprendolls & $12.330,8082$ & 6,755079464 \\
Typic Eutrudepts & Lithic Dystrudepts & $1.211,54522$ & 0,663710284 \\
\hline \multicolumn{2}{c}{ Jumlah } & $182.541,275$ & 100 \\
\hline
\end{tabular}

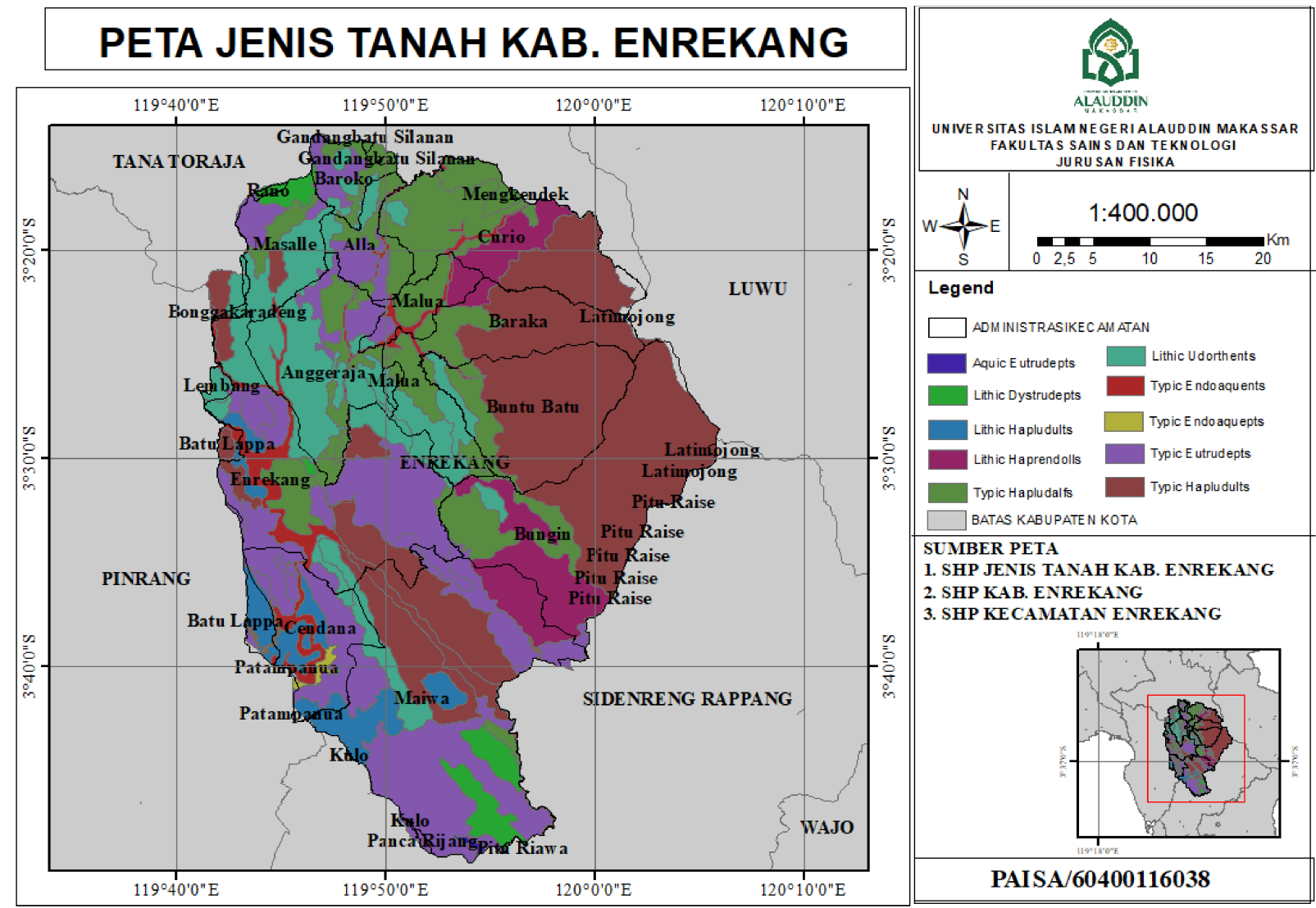

Gambar 4. Peta Jenis Tanah Kabupaten Enrekang.

\section{Kemiringan Lereng}

Peta kemiringan lereng diperoleh dari klasifikasi data DEM. Data tersebut diklasifikasikan menjadi lima kelas yaitu datar, landai, agak curam, curam, dan sangat curam. Daerah dengan kemiringan lereng yang terjal memiliki potensi longsor yang besar dibandingkan dengan daerah yang memiliki kemiringan lereng yang sedang atau pun datar. Kemiringan lereng pada Kabupaten Enrekang dapat dilihat pada Tabel 4 yang merupakan klasifikasi lereng sehingga diketahui kemiringan lereng serta persentase kemiringan lereng di Kabupaten Enrekang dari datar hingga sangat curam. 
Gambar 5 di bawah ini merupakan gambar peta sebaran kemiringan lereng di wilayah Kabupaten Enrekang. Gambar tersebut memperlihatkan daerah dengan kemiringan lereng datar sampai sangat curam dengan memperhatikan warna pada legenda. Warna kuning menunjukan kemiringan lereng datar, warna orange landai, hijau tua agak curam, hijau muda curam dan merah sangat curam.

Tabel 4. Kemiringan Lereng Kabupaten Enrekang.

\begin{tabular}{cccc}
\hline Slope & Klasifikasi & Luas (Ha) & Persentase (\%) \\
\hline $0-8 \%$ & Datar & 62775,47 & 34,34 \\
$8-15 \%$ & Landai & 56196,25 & 30,74 \\
$15-25 \%$ & Agak curam & 47968,37 & 26,24 \\
$25-45 \%$ & Curam & 15430,9 & 8,44 \\
$>45 \%$ & Sangat curam & 419,98 & 0,23 \\
& Jumlah & 182.791 .01 & 100 \\
\hline
\end{tabular}

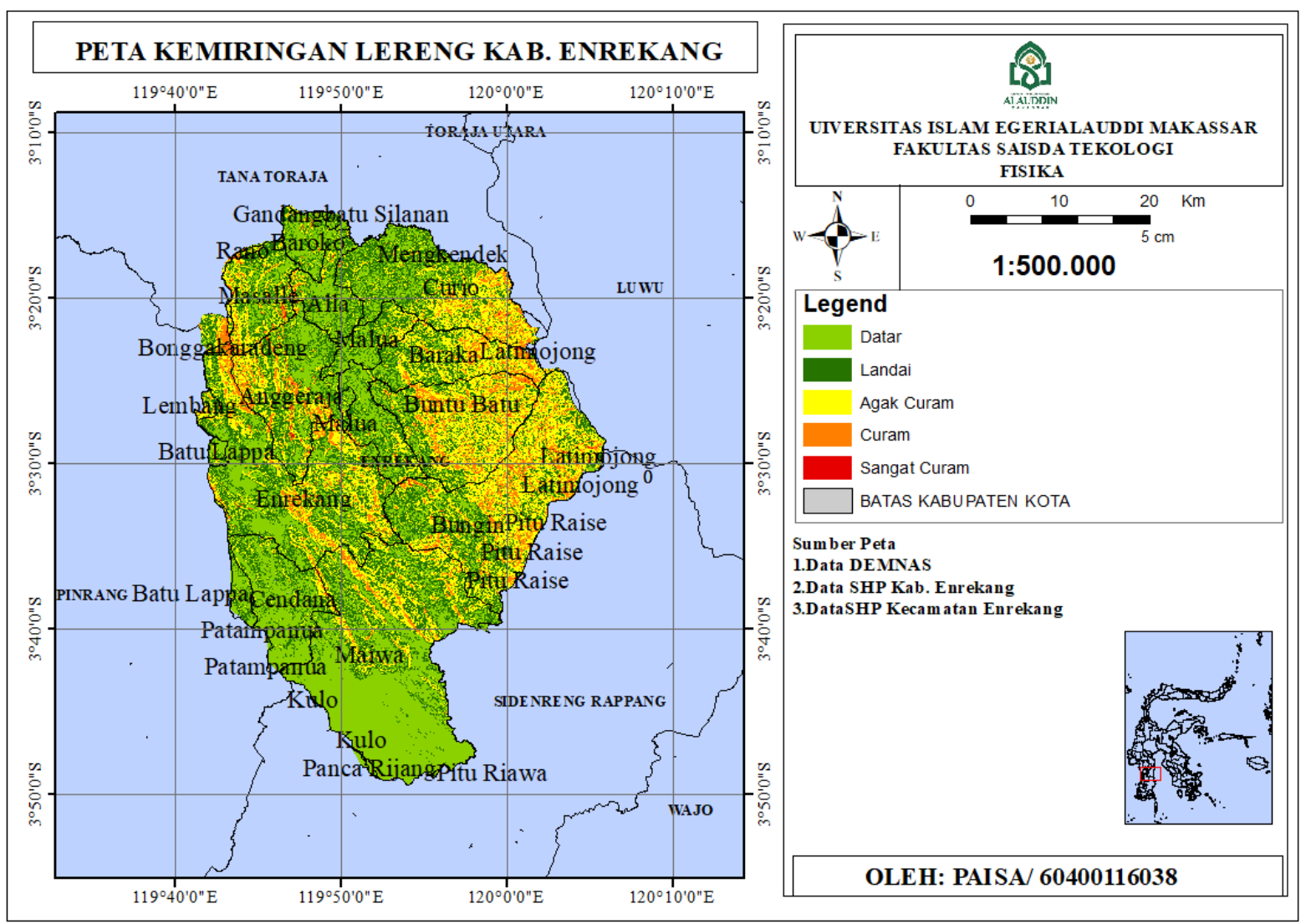

Gambar 5. Peta Kemiringan Lereng Kabupaten Enrekang.

\section{E. Peta Penggunaan Lahan}

Peta penggunaan lahan merupakan hasil overlay shapefile penggunaan lahan Provinsi Sulawesi Selatan dengan shapefile administrasi Kabupaten Enrekang. Kedua data tersebut dipotong untuk menghasilkan peta penggunaan lahan Kabupaten
Enrekang. Peta penggunaan lahan diperlukan sebagai data pendukung untuk mengetahui tingat kerawanan bencana tanah longsor. Di bawah ini Tabel 5 memperlihatkan penggunaan lahan di Kabupaten Enrekang. Sedangkan Gambar 6 merupakan gambar peta sebaran penggunaan lahan di Kabupaten Enrekang. 
Tabel 5. Penggunaan Lahan Kabupaten Enrekang.

\begin{tabular}{lcc}
\hline \multicolumn{1}{c}{ Tipe Penggunaan Lahan } & Luas (Ha) & Persentase (\%) \\
\hline Hutan Lahan Kering Primer & $28.430,03$ & 13,99 \\
Hutan Lahan Kering Sekunder & $35.149,09$ & 17,30 \\
Tanah Terbuka & $1.114,86$ & 0,55 \\
Hutan Tanaman & 104,68 & 0,05 \\
Belukar & $14.075,58$ & 6,93 \\
Pertanian Lahan Kering & $99.967,76$ & 49,19 \\
Savana / Padang rumput & $6.168,05$ & 3,04 \\
Pertanian Lahan Kering Campur & $12.371,65$ & 6,09 \\
Sawah & $5.847,13$ & 2,88 \\
\multicolumn{1}{c}{ Jumlah } & $203.228,83$ & 100 \\
\hline
\end{tabular}

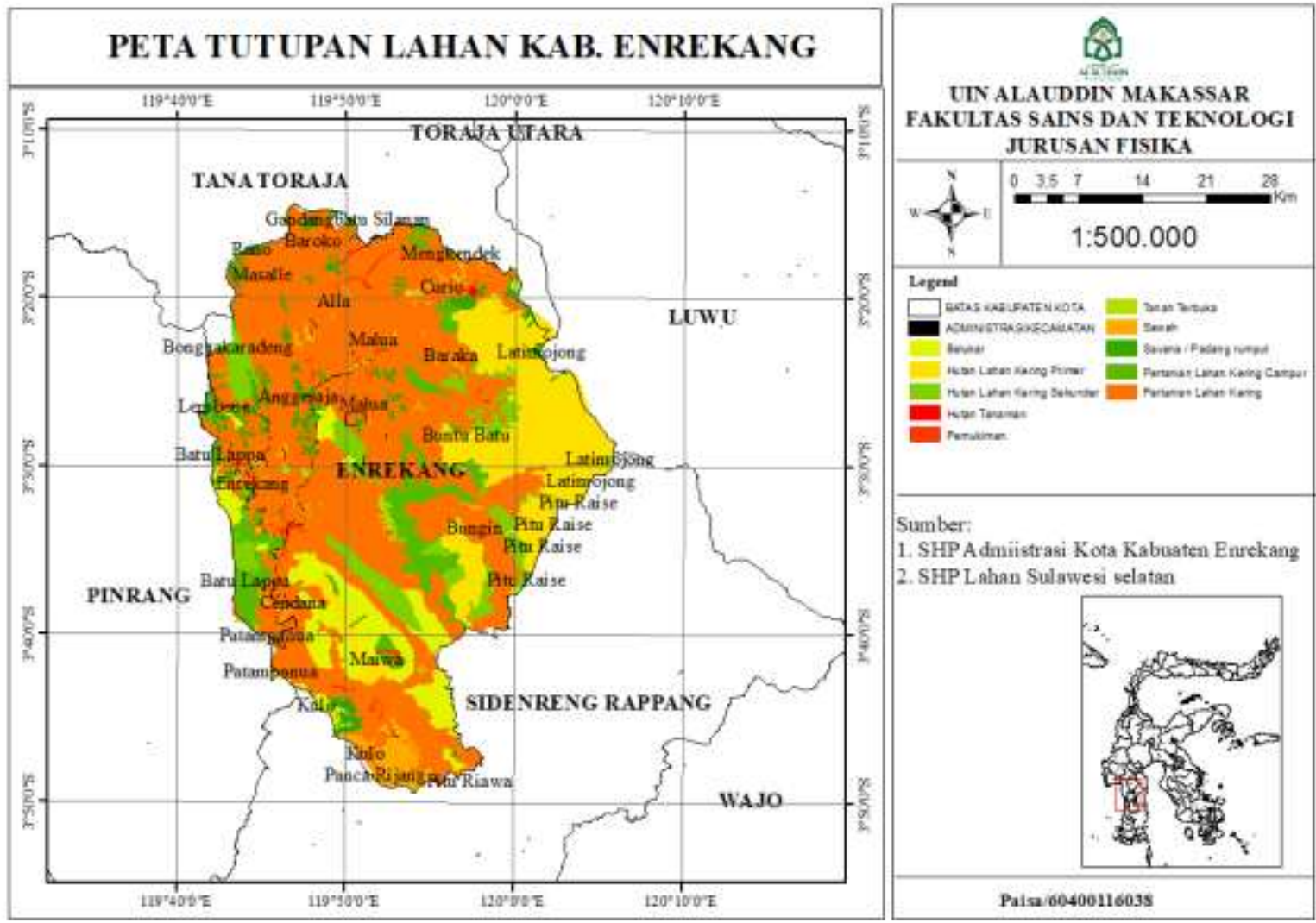

Gambar 6. Peta Tutupan Lahan Kabupaten Enrekang.

\section{F. Peta Vegetasi}

Vegetasi diperoleh dari data Landsat 8 yang dioleh dengan metode bandmath band Red dan band Nir atau band 4 dan band 5 . Kemudian dilakukan pengklasifikasian menjadi tiga kelas yaitu vegetasi kelas rendah, vegetasi kelas sedang dan vegetasi kelas tinggi seperti pada Gambar 7. Vegetasi dengan kelas rendah memiliki warna biru, sedangkan pada kelas sedang memiliki warna coklat dan vegetasi dengan kelas tertinggi berwarna hijau. 


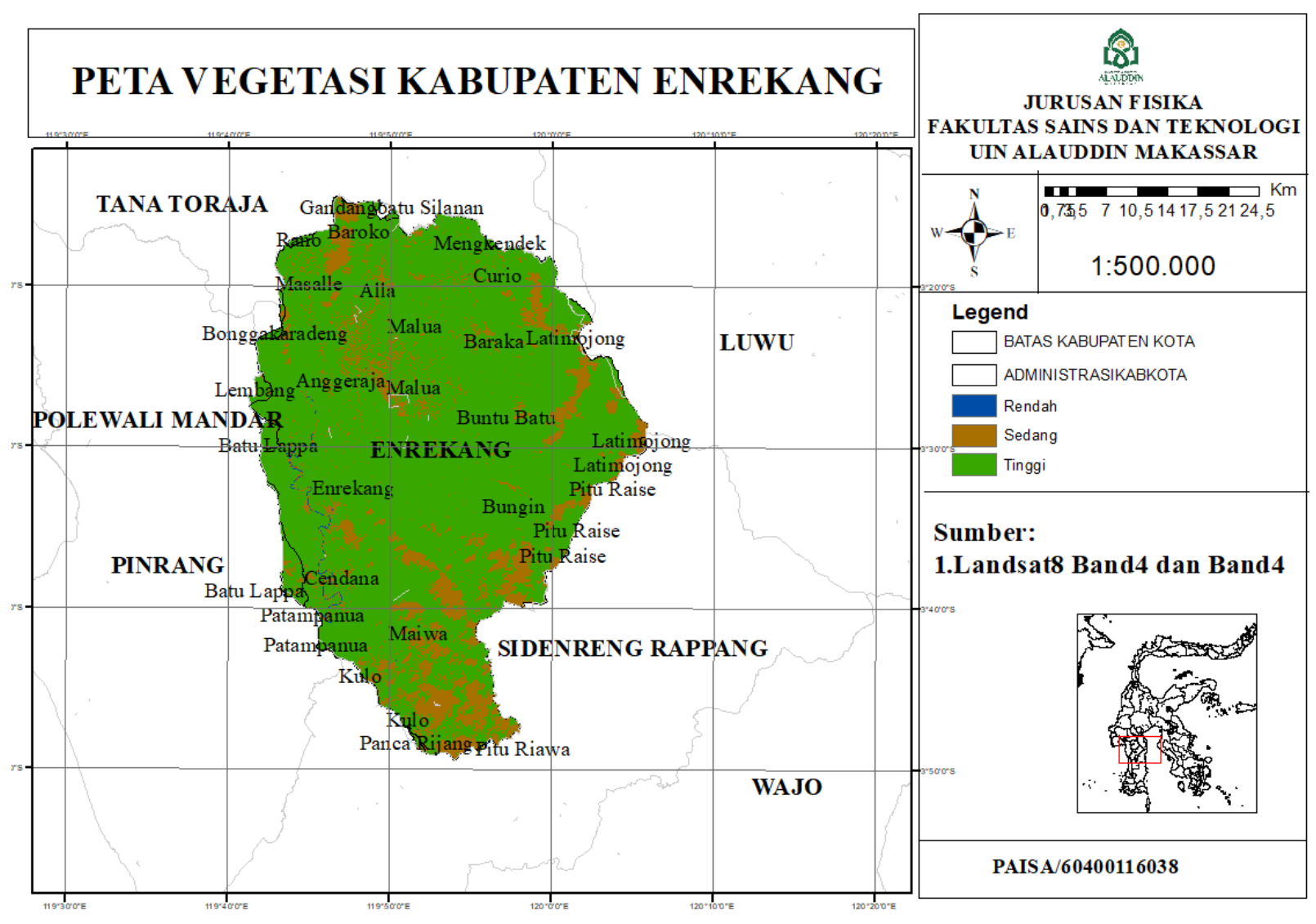

Gambar 7. Peta Vegetasi Kabupaten Enrekang.

\section{G. Peta Daerah Rawan Longsor}

Zona rawan longsor diperoleh dengan cara meng-overlay semua data peta yang telah dibuat. Data tersebut diolah menjadi daerah rawan longsor dengan memberi bobot setiap kelas. Tabel 6 adalah kelas rawan longsor yang diperoleh setelah pembobotan kemudian dianalisis untuk mengetahui persentase terbesar zona bencana longsor di Kabupaten Enrekang.

Gambar 8 merupakan peta rawan longsor di Kabupaten Enrekang. Warna hijau tua menunjukan daerah tidak rawan longsor, hijau muda agak rawan, orange cukup rawan, kuning rawan dan merah sangat rawan.

Tabel 6. Kelas Rawan Longsor.

\begin{tabular}{lcc}
\hline Kelas Rawan Longsor & Luas (Ha) & Persentase (\%) \\
\hline Tidak Rawan & $56.427,05$ & 31,28 \\
Rawan & $101.364,81$ & 56,19 \\
Sangat Rawan & $22.595,003$ & 12,53 \\
\multicolumn{1}{c}{ Jumlah } & $180.386,86$ & 100 \\
\hline
\end{tabular}




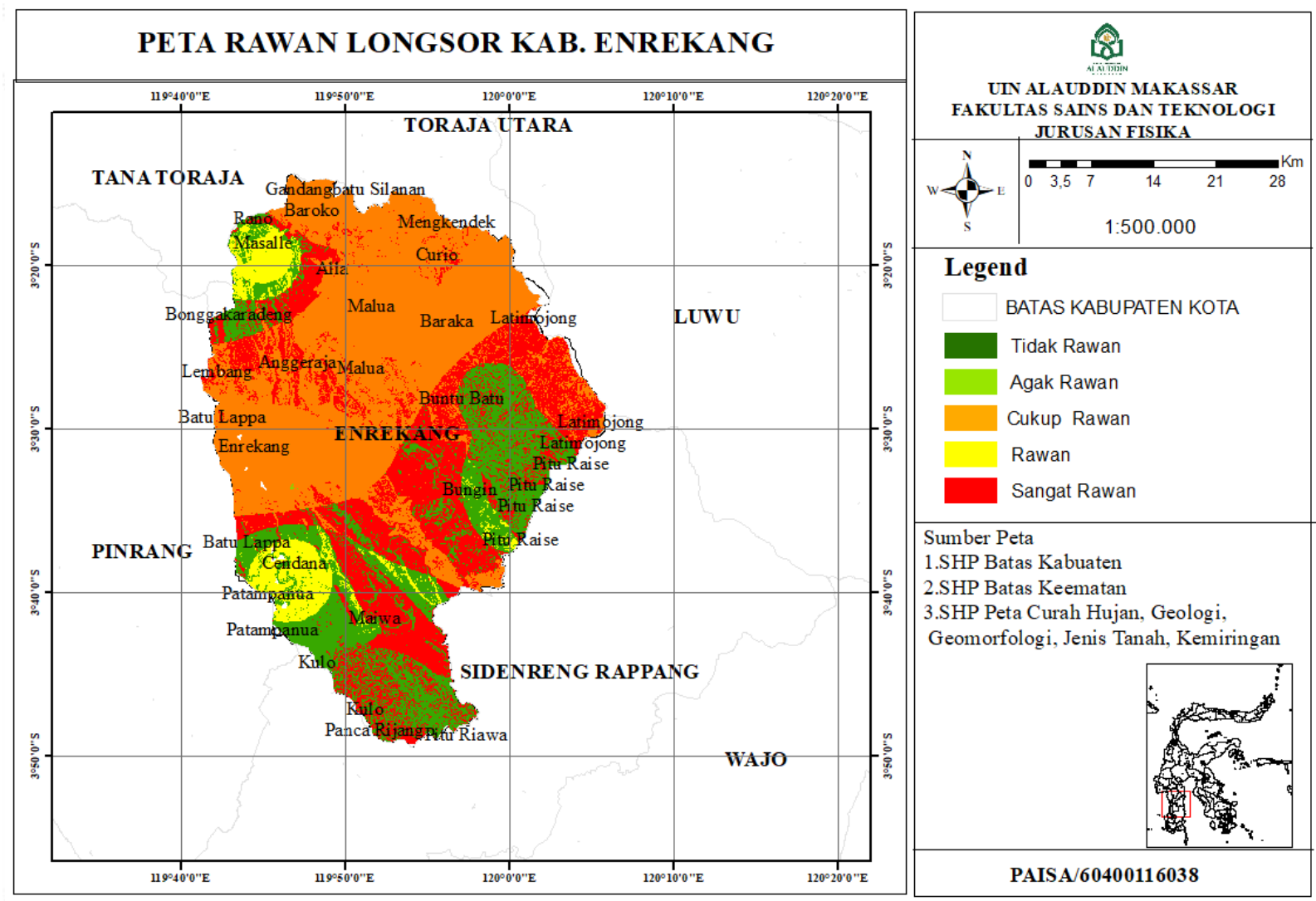

Gambar 8. Peta Derah Rawan Longsor Kabupaten Enrekang.

\section{Kesimpulan}

Berdasarkan hasil pengolahan dan analisis data yang dilakukan di Kabupaten Enrekang, sehingga memperoleh kesimpulan bahwa didapatkan tiga kelas rawan longsor yakni tidak rawan sebesar 31,28\%, meliputi sebagian besar Enrekang, Baraka, Malua, Gadang Batu Silana, Baroko, Mengkedek, Curio, dan sebagian kecil Anggeraja. Kelas rawan sebesar 56,19\% terdiri dari sebagian besar Mulo, Pancara Riaja, Kulo, Pitu Riawa, Pitu Riase, Latimojong, Bungi, Buntu Batu, Alla, Bongkar Adeng, serta sebagian kecil Curi, Mangkedek dan Cendana. Sangat rawan sebesar 12,35\% meliputi Candaa, Maselle, dan sebagian kecil Maiwa, Bungi, Pitu Riase, Latimojong dan Buntu Batu. Data tersebut diperoleh dari penggabungan data curah hujan, kelerengan, jenis tanah, penutupan lahan, dan geologi serta vegetasi sebagai data pendukung.

\section{Daftar Pustaka}

Badan Nasional Penanggulangan Bencana (BNPB). 2019. Daerah Rawan Longsor.

Ati, J.S. 2016. Pemanfaatan Citra Landsat 8 untuk Identifikasi Kawasan Rawan Longsor. Skripsi, ITN Malang.

LAPAN. 2015. Pedoman Pengolahan Data dan Penginderaan Jauh Landsat 8 untuk Mangrove. Jakarta: Pusat Pemanfaatan Penginderaan Jauh.

Laurensz, B., Lawalata, F. dan Prasetyo, S.Y.J. 2019. Potensi Resiko Banjir dengan Menggunakan Citra Satelit (Studi Kasus: Kota Manado, Provinsi Sulawesi Utara). Indonesian Journal of Computing and Modeling. 2(1), pp.17-24. Retrieved from https://ejournal.uksw.edu/icm/articl e/view/2536

Leng, M., Tanesib, J.L. dan Warsito A. 2017. Pemetaan Daerah Rawan 
Longsor dengan Pengindraan Jauh dan Sistem Informasi Geografis di Kabupaten Timor Tengah Utara Provinsi Nusa Tenggara Timur Indonesia. Jurnal Fisika: Fisika Sains dan Aplikasinya. 2(1), pp.2428. Retrieved from https://ejurnal.undana.ac.id/FISA/a $\underline{\text { rticle/view/539 }}$

Selby, M.J. 1985. Earth's Changing Surface: an Introduction to Geomorphology. Oxford [Oxfordshire]: Clarendon Press; New York: Oxford University Press.

SLHD, 2006. Buku 2 Basis Data. Lingkungan. Enrekang: Stasiun Lingkungan Hidup Daerah.

Sutanto. 1987. Penginderaan Jauh Jilid 1. Yogyakarta: Gadjah Mada University Press.

Wahyuni, A., Saka, B., dan Rahmaniah, R. 2019. Mitigasi Bencana Geologi (Gempabumi dan Tanah Longsor Di Kabupaten Toraja Utara dan Tana Toraja dalam Mengurangi Risiko Bencana. Neutrino. 1(2), pp.33 - 38. Retrieved from http://journals.ukitoraja.ac.id/index. $\mathrm{php/neo/article/view/512}$ 